\title{
An Investigation of EFL Students' Essay Writing: Problems and Suggestions: Ambo University First Year Students in Focus
}

\author{
Tamiru Gari Ayana(Principal Author) \\ MA in Teaching English as a Foreign Language (TEFL) \\ Ambo University, College of Social Science and Humanities, Department of English Language and Literature, \\ P.O. Box 19 Ambo, Oromia, Ethiopia
}

\begin{abstract}
It is evident that university EFL students strive for mastery of the four basic language skills. As compared to other skills, writing skills needs much time and effort. It is also one of the language productive skills that play a pivotal role. However, it is considered a difficult skill, particularly in English as a foreign language context where students face many challenges in writing. Thus, the current study was conducted with an aim to investigate problems in Ethiopian first year university students' essay writing. It primarily aimed at investigating challenges students face in EFL essay writing. It also aimed at obtaining suggestions on how to improve Ambo University EFL students' essay writing skills. For this purpose, writing samples were collected from 60 first year undergraduate students and five of the total students were interviewed to collect data on how to improve students' essay writing. The data gathered from the essay were categorized and thematically analyzed, and the interview results were qualitatively analyzed. The findings revealed that students encounter various problems such as faulty sentences, mechanical errors, dangling and misplaced modifiers, wrong use of grammatical structures, vocabulary and others. It was found out that a total of 2030 errors in faulty sentences, mechanics, grammar, vocabulary, and others were the common errors students encountered. The highest number of errors (i.e. $51.54 \%$ ) was made in faulty sentences. Next to faulty sentences, wrong use of mechanics (i.e. $22.46 \%$ ) was the second frequently occurred error. The third common type of errors was other grammatical error (i.e.9.9\%) which was followed by errors in the use of vocabulary $(9.55 \%)$, and other errors $(6.55 \%)$. Based on the findings recommendations were given to teachers, students institutions on remedial actions.
\end{abstract}

Keywords: essay writing, problems or challenges, productive skill, suggestions

DOI: $10.7176 / \mathrm{RHSS} / 10-1-03$

Publication date: January $31^{\text {st }} 2020$

\section{Introduction}

Different scholars agree that a person who is equipped with the writing skill is assumed to get more advantages from a language than a person who cannot write. I assumes in support of this assumption that Kane 1988;4) suggests, "Writing is worth learning. It is of immediate practical benefit in almost any job or career ". Similarly, Millon cited in Neman (1995) is more emphatic to say that "Writing is the greatest tool for thinking ever invented by man". Several merits of writing have also been reported by scholars such as Wyrick (1990) and Kane (1998). According to Kane (1988), writing is a way of growing. In addition to this, Wyrick (1990) states that writing could be vital in that it helps us to lay our ideas for examination and analysis to see and know ourselves in a better way, to communicate with others effectively and to provide a record of thoughts that we may study and evaluate. For the above ideas to come true, in the view of the researcher, improving students writing skills has an indispensible role. Therefore, the aim of this study is to identify the most common challenges of EFL students in essay writing and suggestive solutions for the problems encountered by the students

It is for this reason that writing is incorporated in the language syllabus in areas where language is the medium of instruction or taught as an independent subject as in Ethiopia. However, evidences show that students at any level commit various errors in their written works and many scholars have attempted to pinpoint those errors with the possible reasons behind them. Clifford (1987) cited in Tsegaye (2006) elaborates that the past schooling experience that students passed through have a lot to do with their present writing problems. During schooling, the students might have not been motivated to write meaningfully or sensibly. Dunn 1983 suggests that students' writing becomes insufficient as teachers do not take part in syllabus design and are often presented with textbooks which lacks sufficient writing activities and as a result cannot develop writing proficiency of students.

Students' writing in an EFL classroom context should show their awareness of their own communicative goals, of the reader, and of the writing context. Essay writing, which constitutes a problem for many ESL/EFL students worldwide, is a major challenge for many students of English at Ambo University. Byrne (1991) suggests that writing is difficult task for both native and non-native speakers of English. He also stressed that students face a number of challenges producing correct and appropriate texts since it is often given as homework and therefore unsupported. When the students are given an essay to write as homework, they cannot get support 
both from their peers and instructors as they do in pair or group work in the classrooms.

According to scholars, Byrne (1988), Ur (1996), and Raimes (1983), writing process is a difficult activity because of various reasons. This difficulty of students in writing process is basically caused by psychological, linguistic and cognitive factors. The psychological problem arises from the very nature of writing that it is essentially solitary activity and the fact that we are required to write on our own without the possibility of interaction or the benefit of feedback in itself. The linguistic factor is related to the absence of the prosodic features such as repeating, backtracking, expanding, which are very common in speech are absent in writing. Therefore, writing needs features like choice of sentences, sentence coherence and punctuation which need the effort of the writer to keep the channel of communication open. The other problem, the cognitive factor, states writing is learnt through a process of instructions in which the writer has to master the written form of the language.

The only local works so far available at this researcher's reach was Mamo (1981) who investigated students' problems in essay writing with special reference to grammatical problems of third and fourth year of Addis Ababa university students and Tsegaye(2006) who investigated high school students' problems in writing at Injebara Preparatory School. However, relative emphasis has been given to students' writing by the following researchers. Guta Kedida (1989): spelling errors, Asres Nigus (2005): exploration of the written errors treatment, Getnet Tizazu (1993): the responding behavior of instructors to students writing, and Yonas Adaye (1996): teaching writing as a process.

Despite plenty of approaches to the teaching of writing having evolved from different teaching methods, tackling EFL writing is still one of the most challenging areas for teachers and students. In this regard, Ethiopian students at Ambo University have to pass many academic courses in English which leads to various challenges, especially in their writing skill. As a result, these students still experience some problems in their English essay writing. To the best of my knowledge, most of the studies conducted in the field of essay writing, in Ethiopia, however, mainly focuses on grammatical problems of students in writing skill at high school or precollege level. Only one study, Mamo (1981) conducted the study at university level which deals with specifically grammatical problems of students in essay writing. The current study, therefore, aims at investigating problems that first year EFL undergraduate students at Ambo University encounter while composing their essays in English.

The research was carried out to answer the following research questions:

1. What are the major problems in Ambo University ESL learners' writing skills at undergraduate level?

2. How can first year undergraduate ESL learners' writing skills be improved?

\section{Objective of the study}

The general objective of the study was to investigate problems first year undergraduate EFL students at Ambo University face in essay writing.

Specifically, the study aimed to:

1. Explore problems first year undergraduate EFL students at Ambo University face in essay writing.

2. Investigate ways of improving the students' writing skills.

\section{Materials and Methods}

To answer the research questions, this study employed a qualitative approach to explore the writing problems and suggestions to improve writing skills of EFL undergraduate students in Ambo University. Mixed research design was used in the study. Quantitative design to describe the errors investigated from students' written essays and qualitative design to analyze suggestions of the students' on how to improve their essay writing were used. This study involved collecting essays from EFL undergraduate students in Ambo University, one of the public universities in Ethiopia, who take the course 'Basic Writing Skills', which is offered to all Ambo University first year students, in particular, and Ethiopian universities in general. A total of 60 students from one class were purposively selected to write an essay each. The essay was descriptive with the topic "My Friend's Personal Description" and the students had to write a five paragraph essay using 500 to 700 words. Finally, the researcher collected 60 essays from the students, with about 40,000 words in total. For interview, the researcher selected five students from the class using systematic random sampling technique to inquire them to give their suggestive solutions on ways of improving their essay writing skills. The collected essays were marked and the common errors were identified. Next, these errors were clustered to observe the total of cluster types and cluster tokens in those errors. The results were then tabulated into frequency and percentage.

\section{Data Analysis}

This study aimed at investigating the problems students face in their essay writing and measures to be taken to improve their writing skills. To collect data, document analysis in which sample of written essay was used and students' interview were employed. In the analysis, the data gathered from written samples of students' essay were analyzed quantitatively using frequency and percentage, whereas students' interview was analyzed 
qualitatively.

Table 1: Analysis of Students' Written Essay

\begin{tabular}{|c|c|c|}
\hline Writing Problems & $\begin{array}{l}\text { Frequency } \\
\text { Occurrence }\end{array}$ & $\begin{array}{l}\text { Percentage } \\
(\%)\end{array}$ \\
\hline \multicolumn{3}{|l|}{ 1. Faulty Sentences } \\
\hline - Sentence fragment & 254 & 12.5 \\
\hline - Fused sentences or run-on sentences & 221 & 10.88 \\
\hline - $\quad$ Subject-verb-agreement & 208 & 10.25 \\
\hline $\begin{array}{lllll}\text { - } & \begin{array}{l}\text { Modifiers (Dangling modifiers and misplaced } \\
\text { modifiers) }\end{array}\end{array}$ & 190 & 9.39 \\
\hline - $\quad$ Faulty Parallel structures & 173 & 8.52 \\
\hline Subtotal & 1046 & $\mathbf{5 1 . 5 4}$ \\
\hline \multicolumn{3}{|l|}{ 2. Mechanics } \\
\hline - $\quad$ Spelling & 219 & 10.79 \\
\hline - $\quad$ Punctuation & 237 & 11.67 \\
\hline Subtotal & 456 & 22.46 \\
\hline 3. Grammar & 201 & 9.9 \\
\hline \multicolumn{3}{|l|}{ 4. Vocabulary } \\
\hline - Diction & 92 & 4.53 \\
\hline - Wrong Forms & 102 & 5.02 \\
\hline Subtotal & 194 & 9.55 \\
\hline 5. Others & 133 & 6.55 \\
\hline Total & 2030 & 100 \\
\hline
\end{tabular}

\subsection{Analysis of Written Samples}

The analysis of students essay writing samples revealed a total of 2030 errors in faulty sentences, mechanics, grammar, vocabulary, and others. As can be observed in table1, the highest number of errors (i.e. $51.54 \%$ ) was made in faulty sentences. Next to faulty sentences, wrong use of mechanics (i.e. $22.46 \%$ ) was the second frequently occurred error. The third common type of errors was grammatical error (i.e.9.9\%) which was followed by errors in the use of vocabulary $(9.55 \%)$, and other errors $(6.55 \%)$ (See Table 1).

\subsubsection{Analysis of Errors in Faulty Sentences}

The faulty sentences include basic sentence structures like sentence fragments, run on or fused sentences, subject-verb agreement, wrong use of modifiers, and faulty parallel structures. The major problem is related to errors made in sentence fragments which comprises $12.5 \%$ of the errors, run-on or fused sentences that covers $10.88 \%$, concordance or subject-verb-agreement which is $10.25 \%$, modifier (i.e. $9.39 \%$ ), and faulty parallel structures that is $8.52 \%$ of the total errors made by the students. The common sentence fragment errors were errors related to subject- missing sentences, verb-missing sentences and subordinate clauses without independent clauses. For example, 'Has two brothers' (subject missing), 'Her father a farmer' (verb missing), 'I didn't scored a good result. Because of financial problem' (subordinate clause). 'Because, she do physical exercise every Saturday' (subordinate clause) The second frequently occurred faulty sentence was error of fused sentences. This error is characterized by the absence of punctuation mark at the end of an independent sentence and, as a result, all or some of the sentences in a given paragraph run together without stop. For example, 'My friend lives in Ambo he is a first year student now', 'My friend's name is Bontu Melkamu she was born in 1999 she started her primary education in $2005^{\prime}$. Errors in the fused sentence were followed by errors in concordances in which the students use wrong subject-verb agreement both in number and person. Some examples are, 'He have ('have' for 'has') three brothers and one sister', 'His parents are a farmer' ('a farmer' instead of 'farmers'), 'She usually play ('play' for 'plays') with her friends during her free time' 'Her father teach at a high school'(teaches), 'My friend always do physical exercise at his free time'('do' - 'does'). Regarding modifiers, dangling modifiers, for example, 'Taking the final exams, Aster fainted in the classroom' was one category of the errors. This sentence doesn't specify the person who is taking the exam whether it refers to Aster or somebody else. Another students' problem with regard to modifiers was misplaced modifier in which the modifier wrongly placed in a sentence. One example is: 'My friend likes wearing a jacket that I know from high school'. In this sentence the clause or modifier 'that I know from high school' does not logically modify the subject 'My friend', but the object 'jacket'. Another example is: 'He visits always ('He always visits') his parents'. Faulty parallelism was also one of the problem areas in the students' written essays. They wrote sentences like, 'During his free time, he likes reading, swimming and to watch ('to watch' for 'watching') films', 'He is very clever and success ('success' instead of 'successful') in his education' She was hard worker and effectiveness ('effectiveness' in place of 'effective') in 
all her activities'.

\subsubsection{Analysis of Grammatical and Mechanical Errors}

Mechanical errors are the consequence of quick writing where the focus is on the content rather than the form. Spelling and punctuation errors were also the next problem areas of Ambo University first year EFL students in writing their essays. For instance, errors like 'invaroment' or 'envayiroment' (for 'environment'), 'feaucher', or 'feauture' (for 'future'), 'enginering' or ' inginaring', (for 'engineering), 'lissen' or 'lison' (for 'listen') were some of the common spelling errors made in the essay writing. The other type of error was punctuation errors that include wrong use of comma, full stop, and capitalization. Some of the major errors in this regard were, 'my friend is a very, shy person' (capitalization and wrong use of comma), 'In his free time. he likes watiching films'(wrong use of full stop), 'My friend(apostrophe's is needed) name is Duguma Hirko. he (capitalization) was born in 1984 in West Showa. his (capitalization) father is a farmer and his mother is a house wife'. 'her father is a farmer and her mother is house wife'.

In writing, conveying a meaningful message or information is paramount. In organizing an idea in a meaningful way, in turn, grammar has a pivotal role. However, it was found out that grammar problem is one of the Ambo University first year undergraduate EFL students' difficulties in essay writing. For example, ' Now she was ('was' for 'is') 20 years old', 'She born ('born' instead of 'was born') in 1994 in West Showa', 'If he gets some money, he would have visited ('would have visited' for 'will visit') his family in the vacation'.

\subsubsection{Analysis of Vocabulary and Other Errors}

Vocabulary is another problem area of the students next to grammar in essay writing. In some ways, the ability to write effectively depends upon having an adequate vocabulary. Therefore, the writer must be able to spontaneously recall words that are understood well enough to use correctly. In other words, writing is dependent upon the ability to draw upon words to describe an event. Yonek ( 2008) notes, "variety in selecting words to convey accurate meanings is necessary in speaking and writing, the outgoes of the language arts and at any level, written communication is more effective when a depth of vocabulary and command of language is " ( $p$. 25-26). Nevertheless, Ambo University EFL undergraduate students faced some vocabulary problems such as diction, wrong forms, misuse of homonyms, and confusing words. Diction refers to using the right words at their right place or selecting the right word - or the word that best expresses the author's intent - is a key. A writer must approach the process of choosing the right word with care. For instance, the words 'pretty' and 'gorgeous' need to be appropriately used in their right place in sentences, otherwise, they lead to confusion. Similarly, the frequently occurred errors in the students written essay are as follows: 'She entered ('entered' for 'joined') this university this year', 'He has diploma by ('by' for 'in') English Language teaching'. ' In short, my friend is a good person in front of('in front of' instead of 'before' 'to') all people. Examples of wrong forms are, 'She was graduated in English Language', 'After he completed grade 12, he assigned ('assigned' instead of 'was assigned') to Ambo University', 'She leaved ('leaved' for 'lived') in Adama before she came here'.

The other vocabulary error was misuse of homonyms. Homonyms are words that sound the same, but differ in meaning, spelling and usage. Typical homonyms which were often misused in the students' essay are 'its' instead of 'it's', 'now for 'know', 'knew' for 'new', 'live' for 'leave' etc. Apart from homonyms, confused words which are similar in spelling, sound and meaning, but often confusing, were other problems of students in writing essays. These are, 'quiet tall' instead of 'quite tall', 'there' instead of 'their', 'affect' for 'effect' etc. Errors that were categorized under other problems like errors in the use of cohesive devices, articles and prepositions were also found to be challenges to the students writing. Most essays of the students suffered from lack of cohesive devices that were the most abundant problem in other errors. Finally, articles and prepositions like 'He is a Christians (instead of 'a Christian' or 'Christians')', 'She always has an eggs for her breakfast ('an eggs' for 'eggs')', and 'He learned Ambo High School before he joined university (preposition 'at' should be used)'.

\subsection{Analysis of Students' Interview}

The data from students' interview revealed that there are various ways of improving undergraduate ESL learners' writing skills. The respondents suggested several remedies. They suggested that reading plays a significant role in order to enrich ideas and vocabulary to develop better writing. The time given, by the instructors, in the classrooms in order to make their best effort in expressing themselves on paper was also emphasized. They responded that adequate time is not allocated to practice writing in the classroom. They stressed that most instructors spend much of their time on teaching about writing rather than assisting the students to write their own essays. It was also suggested that adapting a writing culture and providing opportunities for writing practice is so important. It was emphasized that importance should be given to writing as it is given to other language skills such as reading, speaking, grammar and vocabulary.

According to respondents, the assessment technique also required improvement. They replied that the examination system of the instructors do not promote students' writing as essay writing is not part of both the formative and summative evaluation. In most cases, they responded, essay writing is either given as an 
assignment which can be susceptible to plagiarism or even totally ignored. Similarly, the importance of giving effective feedback cannot be denied. Therefore, they replied, positive and constructive feedback at all level of writing has to be given.

Another remedy that was forwarded by the respondents was that the writing module should be modified to motivate learners towards writing. The module was meant for teaching the course 'Basic Writing Skills' which is given to all first year undergraduate students at the university. According to the respondents, the module is not motivating in terms of an arrangement of activities. Finally, the respondents replied that supportive courses that develop their overall language proficiency should be given in order to minimize the problems the students face in essay writing. They recommended that courses that help to improve their vocabulary and grammar skills are highly important.

\section{Findings and Discussions}

The main objective of this study was to investigate problems undergraduate EFL students face in essay writing skills and ways of improving their writing skills. To address the objectives, document analysis, to investigate problems student face in essay writing and, interview, to gather students' suggestion on how to improve their writing skills, were employed. The findings of the writing samples of students essay writing samples revealed that the major problem lies on the errors in faulty sentences which include sentence fragments, run on or fused sentences, subject-verb agreement, wrong use of modifiers, and faulty parallel structures. Mechanics also poses a problem for the students as they faced challenges in using appropriate punctuation and capitalization, and correct spelling. Similarly, students lack grammar skills in order to organize their essay in a meaningful way. According to UR (1988), grammar is an essential language skill for the mastery of language skills. She argues that one cannot use words unless they know how the words should be put together to use the language as accurately as possible for communicative purposes. However, these errors were one of the frequently occurred errors in the essays and affects students' writing skills. The findings also indicated that the subjects of this study had problems in the use of vocabulary like diction, wrong forms, misuse of homonyms, and confusing words. In the study, errors in the use of cohesive devices, articles and prepositions were also found to be challenging to the students' writing.

As findings of the students' interview indicated, these problems and challenges can be resolved by several remedial measures at individual as well as institutional level. At individual level, students and the course instructors have their irreplaceable roles in improving students' essay writing skills. The participants suggested that EFL students have to improve their overall language proficiency skill through improving their reading skills. They also responded teachers should increase students' exposure to writing skills through allocating adequate time for classroom essay. It was also emphasized that instructors should give equal emphasis to writing skills as they give to other language skills, provide immediate and constructive feedback, and change their assessment techniques. At the institution level, the respondents indicated, Ambo University needs to revisit both the teaching module of the writing course, in particular, and the English Language curriculum, in general. They replied that the teaching module has to be modified in the way that it motivates the students toward writing. It was also suggested that these suggestions should be implemented at secondary and intermediate levels so that students minimize these problems and challenges in writing skills at university level.

Based on the study and analysis of the data this paper makes the following recommendations to the concerned bodies.

1. EFL teachers should:

- Give as equal emphasis to writing skill as they give to other language skills by allocating reasonably adequate time to the writing activities.

- Include free writing items in both their formative and summative evaluation.

- Give immediate and constructive feedback to their students' written works.

2. EFL learners needs to:

- Use the best of their effort to commit themselves to essay writing knowing that writing an essay needs their total concentration.

- Have the willing to write freely in writing classes as well as outside of the classrooms.

3. Course syllabus designers also:

- Should give special attention to writing activities in the writing courses in the way the activities motivate the students to involve in essay writing actively.

- May need to revisit the current curriculum to incorporate other supplementary courses that help improve students' overall language proficiency skills which in turn support their writing skills. 


\section{References}

Asres Nigus 2005. An Exploration of the Writing Error Treatment Practices of Intermediate Writing Skills of Bahir Dar University Instructors: AAU, MA Thesis.

Byrne, D. 1998. Teaching Writing Skills. London.London Group UK Limited.

Genet Tizazu 1993. The Responding Behaviar of Sophomore English Instructors: Addis Ababa University, MA Thesis.

Guta Kedida, 1989. An Analytic Study of Patterns of Spelling Errors of Freshman Ethiopian Students at Addis Ababa University: MA Thesis https:/www.ukessays.com/essays/english-language/vocabulary-on-writingin-efl-learners-english-language-essay.php?vref $=1$

Kane, T.1988. The New Oxford Guide to Writing Well. Oxford: Oxford University Press

Mamo Kefele, 1981. Classification and Explanatory Analysis of Student Errors in Advanced English Composition II: Addis Ababa University Naman, B. 1995. Teaching Students to Write. Oxford: Oxford University Press

Raimes, A. 1993. Techniques in Teaching Writing. Oxford: Oxford University Press

Tsegaye, M. (2006). An Investigation of High School Students' Problems in Writing Skills at Injebara Preparatory School: Adis Ababa University, MA Thesis.

UR, P. 1996. Grammar Practice Activities. Cambridge: Cambridge University Press

Wryick, J. 1990. Steps to Writing Well. Holt, Renhalt and Winston, In

Yonas Adaye. 1996. Teaching WRITING AS A Process at First Year level of Addis Ababa University with Special Reference to College English. Addis Ababa University 